\title{
A geração de maus odores na rede coletora de esgotos do município de Pereira Barreto: um problema de saúde pública
}

\section{The creation of bad odors in the sewer system in the city of Pereira Barreto: a public health problem}

\author{
Teodosia Basile Liliamtis \\ Engenheira Química, Mestre e Doutoranda em Saúde Pública pela \\ Faculdade de Saúde Pública da Universidade de São Paulo. \\ E-mail: teodosiaœusp.br \\ Pedro Caetano Sanches Mancuso \\ Professor Doutor do Departamento de Saúde Ambiental da Fa- \\ culdade de Saúde Pública da Universidade de São Paulo. \\ E-mail: mancuso®usp.br
}

\section{Resumo}

A presença de sulfetos, principalmente o de hidrogênio, é responsável pela geração de odores e pelo processo de corrosão nas instalações de coleta e tratamento de esgotos. 0 presente trabalho foi desenvolvido com base em uma pesquisa com a população do município de Pereira Barreto. O resultado desse estudo foi utilizado para identificar e analisar os problemas causados pela geração de maus odores na rede coletora de esgotos local, devido a formação do sulfeto de hidrogênio, focalizando a questão como problema de saúde pública e também avaliar o método de controle de qualidade implantado, para minimizar os intensos odores exalados. Dessa pesquisa, concluiu-se que o método da aplicação do nitrato de amônia mostrou-se eficaz em inibir a produção de concentrações de gás sulfídrico ( $\left.\mathrm{H}_{2} \mathrm{~S}\right)$ superiores a 1,o mg/L. Entretanto, para a região onde se encontra a lagoa de estabilização, a dosagem desse sal apresentou-se inadequada, sendo necessário reavalia-la. Os sintomas apresentados pelos entrevistados decorrentes da exposição ao odor freqüente e ofensivo, como dor de cabeça, náuseas, ardor nasal, tontura e alterações no estado de humor, desapareceram quando o odor passou a ser controlado e sua intensidade diminuída.

Palavras Chave: Odor; Gás sulfídrico; Nitrato de amônia; Saúde Pública. 


\section{Abstract}

The presence of sulfides, particularly hydrogen sulfide, is responsible for the emanation of odors and corrosive attack on pipe line of wastewater treatment facilities. The present research was developed based on a research with the population of the city of Pereira Barreto. The result of this study has been used to identify and analyze the problems caused by the generation of bad odors in the local sewerage system, due to the formation of hydrogen sulfide, focusing on it as a public health problem, and also evaluating the quality control method implemented to reduce the emanation of intense odors. This research concluded that the nitrification method with ammonia nitrate is efficient to inhibit the production of sulphydric gas $\left(\mathrm{H}_{2} \mathrm{~S}\right)$ concentrations over 1,o mg/L H S. However in, the area where the stabilization lagoon is found, the dosage of said salt was inadequate, therefore, it is necessary to evaluate it again. The symptoms presented by the interviewed people who had been exposed to the frequent and offensive odors were: headache, nausea, nose irritation, dizziness and mood alterations. These symptoms disappeared as soon the odor was controlled and the intensity was reduced.

Key Words: Odor; Sulphydric Gas; Ammonia Nitrate; Public Health.

\section{Introdução}

Ao contrário de uma estação de tratamento de água, a implantação de uma estação de tratamento de esgotos em áreas urbanizadas tem sido sistematicamente rejeitada pela população local por um único problema: a geração de odores que essas instalações propiciam.

Freqüentemente tem-se observado a escolha de locais inadequados, do ponto de vista de engenharia, em decorrência dessa não aceitação. São raros os estudos voltados para a solução desse problema, salientandose os trabalhos de Gasi (1984), da Companhia de Saneamento Básico do Estado de São Paulo (SABESP) e de Takahashi (1983).

A exalação dos odores associada aos sistemas de esgotos urbanos é uma questão extremamente complexa, constituindo-se num problema de engenharia e de Saúde Pública ainda não resolvido.

Segundo esses autores, uma causa importante da exalação de odores pelas coleções de águas residuárias é a geração descontrolada de sulfetos, principalmente ao sulfeto de hidrogênio $\left(\mathrm{H}_{2} \mathrm{~S}\right)$. A presença desse composto é também responsável pela corrosão das tubulações de concreto nas instalações de tratamento de esgotos.

Freqüentemente o processo de geração de odores nos esgotos tem origem na presença de sulfetos, principalmente em decorrência da atividade biológica, que também favorece a produção de gases não derivados de sulfetos, que podem ser odoríferos ou não.

Em algumas situações, a produção de odores nos esgotos não resulta de reações químicas ou atividades biológicas, mas da introdução de fatores externos como os despejos industriais.

De acordo com o Guia de Primeiros Socorros para o Sulfeto de Hidrogênio da Environmental Protection Agency (E.P.A. 2001), a toxicidade do $\mathrm{H}_{2} \mathrm{~S}$ ocorre por inalação ou pelo contacto com a pele e olhos. Os efeitos na saúde humana decorrentes de exposição aguda, são: taquicardia, palpitações cardíacas, arritmias cardíacas, bronquites, edemas pulmonares, depressão respiratória e até paralisia respiratória.

Entre os efeitos neurológicos citam-se: vertigem, irritabilidade, dor de cabeça, tontura, tosse, convulsões e até estado de coma. Normalmente esses sintomas são acompanhados de náuseas, vômitos e diarréia. 
Além disso, exposição ao gás sulfídrico pode também provocar irritação na pele, lacrimejamento, perda gradativa da percepção de odores, fotofobia e visão embaçada.

Apesar da pobreza de publicações específicas, existe uma preocupação crescente com relação à exposição de humanos aos odores provenientes dos sistemas de esgotos domésticos. Em nosso país a problemática da emissão de odores provenientes de fontes de poluição como plantas industriais, usinas de tratamento de resíduos sólidos e estações de tratamento de esgotos, não tem sido estudada de forma sistemática, em que pese a existência do limite de lançamento de sulfetos em sistema de esgotos de 1,o mg/L no artigo 19-A no Decreto Estadual n 8.468 de 8 de setembro de 1976.

As soluções de engenharia que têm sido propostas para este problema são: injeção de ar, aplicação de oxigênio, adição de cloro, adição de peróxido de hidrogênio, adição de permanganato de potássio, adição de sais de ferro, aumento do pH, adição de antraquinona, adição de ozônio, agentes mascarantes, lavagem de gases, adsorção em carvão ativado, biofiltros, enclausuramento, incineração, ventilação, radiação ultravioleta, barreiras de descargas dielétricas, fotocatálise heterogênea e a aplicação de nitrato de amônia. Esta última, objeto de avaliação neste trabalho.

\section{Objetivo}

Analisar o impacto da implantação da aplicação do nitrato de amônia como inibidor da produção de gás sulfidrico, na saúde e na capacidade de percepção de odores dos moradores circunvizinhos de uma estação de tratamento de esgoto sanitário.

\section{Metodologia}

\section{Local de estudo}

Em 1979, a CESP (Companhia Energética de São Paulo) iniciou a construção da Usina Hidroelétrica de Três Irmãos, no município de Pereira Barreto, com a finalidade de exploração do rio Tietê para a produção de energia elétrica. Entretanto, a obra concluída em março de 1991, produziu sérios danos ao meio ambiente e que foram apontados no Estudo de Impacto Ambiental
(EIA) do empreendimento. Dentre eles ressalta-se a elevação do lençol freático com elevada taxa de infiltração no sistema de coleta de esgoto urbano que entrou em colapso.

Posteriormente, em 1983, o antigo e precário sistema de coleta e tratamento de esgotos sanitários que atendia cerca de $63 \%$ da população urbana da cidade foi reformulado.

O novo sistema é formado por cinco sub-bacias de esgotamento com vazão total de $8.800 \mathrm{~m}^{3} /$ dia. Cada uma conta com uma estação elevatória que recalca seus efluentes para a sub-bacia vizinha até um emissário, que conduz os esgotos a uma estação de tratamento biológico constituída por um conjunto de lagoas de estabilização (anaeróbia e facultativa), de onde o efluente tratado é encaminhado para o lago da Usina Hidroelétrica de Três Irmãos, a jusante da cidade.

Em novembro de 1991, a Promotoria Pública do Meio Ambiente entrou com uma Ação Civil Pública Ambiental Cautelar (Processo $n^{\circ} 318 / 91$ da $2^{\circ}$ Vara da Comarca de Pereira Barreto) contra a CESP por danos causados ao meio ambiente, estipulando multas e prazos para a solução de vários problemas apontados.

Entre os danos ambientais apontados, destacavase o odor desagradável produzido e exalado pelo esgoto em todas as estações elevatórias, nas caixas de passagens em algumas regiões da cidade e dentro das residências.

Da análise do desempenho hidráulico do sistema coletor realizado pela CESP constatou-se que existiam vários fatores que poderiam propiciar a decomposição de materiais orgânicos com desprendimento de gás sulfídrico, antes do esgoto atingir o sistema de tratamento. São eles:

a) a elevada temperatura do esgoto, em torno de $35^{\circ} \mathrm{C}$. Nessa temperatura há um aumento da velocidade de decomposição anaeróbia da matéria orgânica. Além disso, a solubilidade do gás sulfídrico é inversamente proporcional à temperatura;

b) o elevado teor de sulfato existente na água de abastecimento;

c) trechos da rede coletora, com baixas declividades que propiciam um aumento no teor de sulfetos, em função do depósito de matéria orgânica, fato agravado pela temperatura do esgoto. Cerca de $7,5 \%$ da extensão da rede urbana apresentaram esse problema; 
d) a existência de diversas obstruções parciais ou totais de trechos da rede, que dificultam o escoamento, provocando deposições de matéria orgânica que podem entrar em decomposição. Esse problema de obstrução está relacionado com as ligações indevidas, caixas de gordura ou passagens mal construídas (ou ligações diretas sem sifão) que acabam carreando grandes quantidades de areia e terra para o sistema coletor de esgotos;

e) falhas nos trechos hídricos das instalações prediais de esgoto e a existência de ralos de drenagem pluvial ligados indevidamente ao sistema, sem fecho hídrico, bem como a não existência de sistema de ventilação nas redes das casas.

As medidas corretivas necessárias e que foram implantadas para amenizar o problema de odor gerado pelo esgoto em Pereira Barreto, propostas pela CESP no período anterior a 1995, foram:

a) limpeza da rede coletora e das elevatórias para eliminação dos depósitos e obstruções existentes;

b) rebaixamento do nível das bóias de acionamento dos conjuntos de recalque das elevatórias, para diminuir o intervalo de tempo de retenção do esgoto;

c) implantação de um programa de limpeza constante dos cestos de retenção de sólidos das estações elevatórias;

d) instalação de caixas de gordura;

e) remanejamento de todos os trechos da rede coletora com declividades baixas; e,

f) estabelecimento de programa de desconexão dos ralos de drenagem ligados ao sistema de esgotos.

Apesar da implantação dessas medidas, a exalação dos odores continuaram ensejando a busca de outras soluções junto a SABESP, que havia pesquisado o controle de odores por adição de nitrato de amônia na cidade de Santos, com excelentes resultados.

Assim, a CESP com a supervisão da SABESP, implantou um campo experimental em Pereira Barreto com a finalidade de resolver dois problemas: exalação de odores e corrosão.

Logo de início foi estabelecido que as elevatórias e a lagoa de estabilização seriam pontos de aplicação de nitrato e de monitoramento, pois próximo a estes locais verificava-se o maior número de reclamações.
Os parâmetros analisados nas amostras coletadas foram:

a) temperatura ambiente e do esgoto $\left({ }^{\circ} \mathrm{C}\right)$ : determinada por meio de um termômetro de mercúrio;

b) pH: método eletrométrico;

c) potencial de oxi-redução $(\mathrm{mV})$ : determinada por pHmetro digital com eletrodo específico (BRAILE \& CAVALCANTI, 1993);

d) teor de sulfeto de hidrogênio (mg/L): determinação qualitativa que consiste na reação da amostra de esgoto com acetato de chumbo e utilização de $\mathrm{CO}_{2}$ como catalizador (Standard Methods for the Examination of Water and Wastewater -CLESCERI et al. 1992).

Atualmente o nitrato é aplicado em 11 locais e o controle é feito diariamente, em três horários diferentes, e 14 pontos de monitoramento, numa freqüência semanal.

\section{Instrumento de coleta de dados}

O instrumento utilizado para a coleta de dados para identificar os efeitos do odor na saúde das populações circunvizinhas a ETE de Pereira Barreto, foi um questionário com perguntas fechadas e de contato direto entre entrevistador e entrevistado.

Foram elaboradas 20 questões objetivas, divididas nos seguintes itens:

Identificação: data, nome do entrevistado, sexo, idade e endereço.

Urbanidade: tempo de moradia, localização do imóvel em relação a outras fontes potenciais de incômodos (cemitério, lixões, indústrias etc.).

Descrição do odor: localização do entrevistado quando da percepção do odor, classificação do odor antes da solução do problema, descrição do odor, permanência do odor na vizinhança, percepção atual do odor e classificação do odor após o controle do problema.

Problemas de saúde causados pelo odor: problemas de saúde que o entrevistado já tinha, problemas de saúde que o entrevistado veio a manifestar após sua exposição ao odor e insistência dos problemas de saúde surgidos após o controle do odor.

Questões ligadas à empresa de saneamento: conhecimento acerca da empresa prestadora dos serviços de saneamento, conhecimento acerca das providências do órgão responsável com relação ao problema de odor 
e forma de manifestação adotada pelo entrevistado para reclamar do odor.

\section{Plano de amostragem}

Para aplicação do questionário foram adotados os seguintes critérios estratégicos para a escolha dos entrevistados:

- as residências escolhidas situam-se num raio de cerca de $500 \mathrm{~m}$ do foco de propagação, no caso as estações elevatórias 1, 2, além de um poço de visita (P.V.) na região central de Pereira Barreto. Este raio foi fixado estudando-se o histórico das reclamações e,

- os domicílios em que os moradores possuem um tempo de residência no imóvel de pelo menos 5 anos. Este valor foi estipulado para avaliar o odor nas áreas críticas estabelecidas no presente trabalho, antes e após a aplicação do nitrato de amônia, utilizando-se uma escala de intensidade de odor.

O tipo de amostragem adotada é dita amostragem não probabilística intencional, ou seja, as unidades que compõem a amostra são escolhidas pelo pesquisador, não possibilitando, pelos resultados obtidos nesta amostra, uma generalização para a população “normal” (Rudio, 1989). Além disso, considerou-se para fins de pesquisa, o domicílio como unidade amostral.

Na aplicação do questionário foram adotados os seguintes procedimentos básicos:

- quando da abordagem dos entrevistados, foram dadas informações referentes à pesquisa, objetivo e procedência;

- foram respeitados os indivíduos que preferiram, por qualquer que fosse o motivo, não responder ao questionário, tomando-se a residência imediatamente seguinte;

- no caso de residência fechada (ausência de moradores), foi considerada a residência mais próxima;

- aos entrevistados garantiu-se a manutenção de sua identidade em anonimato, quando da publicação dos resultados da pesquisa, podendo responder livremente às questões, sem medo de ficarem expostos à críticas ou represálias de quaisquer ordem ou procedência.
Foram realizadas 17 entrevistas, com uma média de duração de 30 minutos cada uma. 0 questionário foi aplicado no período de 11 a 13 de julho de 2001.

\section{Análise dos dados}

$\mathrm{Na}$ análise dos resultados, optou-se por abordar as questões referentes aos efeitos do odor na saúde da população e a descrição do odor antes e depois da alternativa escolhida pela CESP para solucionar o problema de geração de odor intenso em Pereira Barreto.

\section{Resultados}

\section{Identificação dos entrevistados}

Com relação à variável sexo dos entrevistados, podese afirmar que a disposição feminina em responder ao questionário foi bem maior que a masculina. 0 número de mulheres (10) correspondeu a 58,o \% do total das entrevistas, e o número de homens (7) foi de $41,2 \%$ do total.

De acordo com a variável idade, os 17 entrevistados estudados ficaram divididos em:

Faixa etária A de 16-35 (anos): 2 (11,8 \%)

Faixa etária B de 36-55 (anos): 7 (41,2 \%)

Faixa etária C acima de 56 (anos): 8 (47,o \%)

\section{Urbanidade}

Quanto ao tempo de moradia dos entrevistados no imóvel, 17,65 \% moram de 5 a 10 anos no imóvel, 17,65 $\%$ de 10 a 15 anos, $11,76 \%$ de 15 a 20 anos e $52,94 \%$ moram há mais de 20 anos no mesmo imóvel.

\section{Descrição do odor}

Dos entrevistados, 29,41 \% disseram que se encontravam dentro de suas residências quando sentiram pela primeira vez o odor proveniente das estações elevatórias ou do poço de visita, e 70,59 \% disseram que estavam fora de casa quando perceberam o odor pela primeira vez.

Com relação à intensidade do odor antes da aplicação do nitrato de amônia tem-se:

- A maioria das mulheres (6 entrevistadas, perfazendo $60 \%$ do total feminino), quanto a maioria dos ho- 
mens (5 entrevistados, perfazendo 71,4 \% do total masculino) classificaram o odor como forte na cidade;

- Para os grupos etários considerados, foram obtidos os seguintes resultados:

- Forte: $100 \%$ para a faixa etária A contra 71,4 \% para a faixa B e $50 \%$ para a faixa C;

- Muito forte: o \% para a faixa etária A contra 28,6 \% para a faixa B e $50 \%$ para a faixa C.

Quanto ao quesito descrição do odor, 88,24 \% dos indivíduos pesquisados caracterizaram-no como de "ovo podre", 5,88 \% referiram que era de "peixe" e 5,88 \% não conseguiram descrevê-lo.

Quanto à permanência do odor na vizinhança, obtiveram-se as seguintes variações de opiniões:

- Semanas: o \% das mulheres contra o \% dos homens;

- Meses: 40 \% das mulheres contra 57,1 \% dos homens; - Anos: 60 \% das mulheres contra 42,9 \% dos homens.

Ainda com relação a esse indicador, o desempenho dos grupos etários estudados apontou (Tabela 1):

Tabela I- Percentagem de entrevistados segundo a permanência do odor na vizinhança e grupo etário.

\begin{tabular}{|l|c|c|c|c|}
\multirow{2}{*}{ Crupo etário } & \multicolumn{3}{|c|}{ Permanência do odor na vizinhança } & \multirow{2}{*}{ Total } \\
\cline { 2 - 5 } & semanas & meses & anos & $100 \%$ \\
\hline B & $0 \%$ & $50,0 \%$ & $50,0 \%$ & $100 \%$ \\
\hline C & $0 \%$ & $28,6 \%$ & $71,4 \%$ & $100 \%$ \\
\hline
\end{tabular}

Durante a entrevista, 94,1\% (16) dos entrevistados afirmaram que ainda sentem o odor advindo das estações elevatórias próximas às suas residências. Somente 5,9 \% (1) dos entrevistados disseram que não sentem mais nenhum odor.

Entretanto, quando perguntado o quão forte o odor é hoje (em 2001), a opinião de ambos os sexos se dividiu da seguinte forma:

- Não perceptível: 10 \% das mulheres contra o \% dos homens;
- Muito fraco: $10 \%$ das mulheres contra o \% dos homens;

- Fraco: 40 \% das mulheres contra 57,1 \% dos homens; - Moderado: 40 \% das mulheres contra 42,9 \% dos homens;

- Forte: o \% das mulheres contra o \% dos homens;

- Muito forte: o \% das mulheres contra o \% dos homens.

Para os grupos etários considerados foram obtidos os seguintes resultados, conforme Tabela 2.

Tabela 2- Percentagem de entrevistados segundo a classificação do odor em 200 l e grupo etário.

\begin{tabular}{|c|c|c|c|c|c|c|c|}
\hline \multirow{2}{*}{ Grupo etário } & \multicolumn{6}{|c|}{ Classificação do odor em 2001} & \multirow{2}{*}{ Total } \\
\hline & imperceptivel & muito fraco & fraco & moderado & muito forte & forte & \\
\hline A & $0 \%$ & $0 \%$ & $50,00 \%$ & $50,00 \%$ & $0 \%$ & $0 \%$ & $100 \%$ \\
\hline B & $14,28 \%$ & $0 \%$ & $42,86 \%$ & $42,86 \%$ & $0 \%$ & $0 \%$ & $100 \%$ \\
\hline C & ०\% & $12,5 \%$ & $50,00 \%$ & $37,50 \%$ & $0 \%$ & $0 \%$ & $100 \%$ \\
\hline
\end{tabular}




\section{Efeitos do odor na saúde}

Com relação aos sintomas que os entrevistados manifestaram, decorrentes de sua exposição freqüente ao odor, percebe-se que as mulheres apresentaram uma maior susceptibilidade a problemas de saúde que os homens.

Para os grupos etários pesquisados, destacam-se como os mais sensíveis os indivíduos que pertencem a faixa B, seguidos pelos das faixas $\mathrm{C}$ e A.

A maioria dos entrevistados (94,1\%) respondeu que sintomas como dor de cabeça, ardor nasal, náusea, alterações do estado de humor e tontura desapareceram assim que o odor intenso foi controlado pelo nitrato de amônia.

\section{Discussão}

No presente estudo, o fato de que o odor em Pereira Barreto, antes da aplicação do nitrato de amônia, tenha sido classificado como forte e em 2001 como fraco, comprova que o método de nitrificação é eficiente no seu controle.

O odor descrito como de "ovo podre", pela maioria dos indivíduos pesquisados, é atribuído ao gás sulfídrico $\left(\mathrm{H}_{2} \mathrm{~S}\right)$ que, como foi visto, é o principal responsável pela exalação de odores desagradáveis nas estações de tratamento de esgotos.

As diferentes opiniões obtidas para o tempo de permanência do odor na vizinhança, são devido ao fato de que o sistema olfativo de algumas pessoas é mais demorado do que o de outras para adsorver as substâncias odoríferas no estado de vapor ou gasoso (WPCF 1979).

Torna-se importante apontar que a população conviveu com o problema do odor proveniente das estações elevatórias durante vários anos, até que o órgão responsável pelo saneamento tomasse alguma providência.

A literatura específica menciona que o odor proveniente do gás sulfídrico produz uma grande variedade de efeitos emocionais e físicos. Este estudo permitiu constatar que os sintomas mais freqüentes referidos pelos entrevistados, em ordem decrescente, foram dor de cabeça, ardor nasal, náusea, alterações do estado de humor e tontura.
Vale comentar que esses sintomas desapareceram assim que a aplicação do nitrato de amônia foi implantada no sistema de esgotos da cidade, minimizando os odores.

As mulheres se mostraram mais susceptíveis aos efeitos do odor, provavelmente pelo fato de existir uma maior ligação feminina com a residência e seu entorno (o bairro, a vizinhança, entre outros).

A resposta das pessoas aos odores é variável, como foi mostrada nesta pesquisa. Essa variabilidade é resultado de diferentes percepções de odores (a percepção varia devido às diferentes classes de compostos odorantes). Além do mais, o fato de aceitar ou rejeitar um odor depende muito das experiências anteriores, das circunstâncias nas quais é sentido, da idade, saúde e atitudes do receptor humano.

Deve-se ressaltar que os resultados apresentados precisam ser encarados como uma tendência e não uma regra, pelo fato da amostragem adotada para a aplicação do questionário ser não probabilística intencional.

Outros trabalhos devem ser realizados, como estudos epidemiológicos (demonstrativos dos efeitos de médios e longos prazos relacionados à Saúde Pública). Assim, problemas relacionados às exposições contínuas de seres humanos à substâncias odorantes, como os funcionários de ETEs, além de moradores, transeuntes e trabalhadores em áreas próximas às estações de tratamento de esgotos, devem ser priorizados à luz da Saúde Pública e Ambiental.

\section{Referências Bibliográficas}

BRAILE, P. M.; CAVALCANTI, J. E. W. A. Manual de tratamento de águas residuárias industriais. São Paulo: CETESB- Companhia de Tecnologia de Saneamento Ambiental, 1993.

CLESCERI, L. S. et al. Standard methods for the examination of water and wastewater. 18. ed. Washington: American Public Health Association, 1992.

COMPANHIA DE SANEAMENTO BÁSICO DO ESTADO DE SÃO PAULO (SABESP). Aplicação de nitrato de amônia para controle de odor na rede coletora de esgotos de Santos e São Vicente. São Paulo, 1987. (Relatório Técnico). 
ENVIRON MENTAL PROTECTION AGENCY (E. P. A.). Emergency first aid treatment guide for hydrogen sulfide. Disponível em: <http://www.epa.gov/ swercepp/ehs/firstaid/7783064.txt > Acesso em: 1 Aug. 2001.

GASI, T. M. T. et al. Controle de odores em sistemas de esgotos. Revista DAE, São Paulo, v. 44, n. 137, p. 122143, jun. 1984.

RUDIO, F. V. Introdução ao projeto de pesquisa científica.13. ed. Petrópolis. Vozes Ltda, 1989.

SÃO PAULO (Estado). Decreto Estadual N. 8.468, de 8 de setembro de 1976. Aprova o Regulamento da Lei n. 997, de 31 de maio de 1976, que dispõe sobre a Prevenção e o Controle da Poluição do Meio Ambiente. Art. 19-A: Estabelece critérios para o lançamento de efluentes de qualquer fonte poluidora em sistemas de esgotos. Disponível em:<http://www.ambiente.sp.gov.br/leis_internet/ 76_8468.zip> Acesso em: 18 out. 2002.
TAKAHASHI, A. Sulfetos em interceptores de esgotos: ocorrência, medidas preventivas e corretivas. São Paulo, 1983. Dissertação (Mestrado em Engenharia) - Escola Politécnica, Universidade de São Paulo.

(WPCF) WATER POLLUTION CONTROL FEDERATION. Odor control for wastewater facilities. Washington (DC), 1979. (WPCF Manual of Practice, 22).

\section{Agradecimentos}

Ao tecnólogo em saneamento Antônio Dirceu Pigatto Azevedo da Companhia de Saneamento Básico do Estado de São Paulo, SABESP, que contribuiu para a realização deste trabalho. Ao engenheiro Carlos Cesar Aquino Garcia do Departamento de Serviços de Esgoto da Companhia Energética de São Paulo, CESP, pela viabilização da visita a ETE de Pereira Barreto, pelas informações e pelas plantas. 